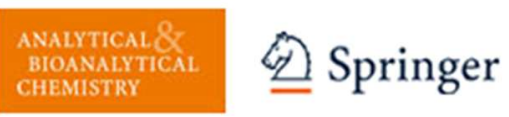

\title{
Sensitive Gluten Determination in Gluten Free Foods by an Electrochemical Aptamer-based Assay
}

\begin{tabular}{|r|l|}
\hline Journal: & Analytical and Bioanalytical Chemistry \\
\hline Manuscript ID: & ABC-00407-2015.R1 \\
\hline Type of Paper: & Research Paper \\
\hline Date Submitted by the Author: & n/a \\
\hline Complete List of Authors: & $\begin{array}{l}\text { Amaya-González, Sonia; Universidad de Oviedo, Química Física y Analítica } \\
\text { de los Santos Álvarez, Noemi; Universidad de Oviedo, Dpto Química Física } \\
\text { y Analítica } \\
\text { Miranda Ordieres, Arturo; Universidad de Oviedo, Química Física y } \\
\text { Analítica; University of Oviedo, Facultad de Ciencias, Dept. de Química } \\
\text { Fisica y Analítica; } \\
\text { Lobo Castañón, Maria-Jesus; Universidad de Oviedo, Quimica Fisica y } \\
\text { Analitica }\end{array}$ \\
\hline Keywords: & \begin{tabular}{l} 
Bioanalytical methods, Bioassays, Electroanalytical methods \\
\hline
\end{tabular} \\
\hline
\end{tabular}




\section{Sensitive Gluten Determination in Gluten Free Foods by an Electrochemical}

\section{Aptamer-based Assay}

Sonia Amaya-González, Noemí de-los-Santos-Álvarez, Arturo J. Miranda-Ordieres,

María Jesús Lobo-Castañón*

Departamento de Química Física y Analítica. Universidad de Oviedo. Julián Clavería 8, 33006 Oviedo. Spain

* Corresponding author

Phone: +34985106235

Fax: +34985103125

e-mail: mjlc@,uniovi.es

Other authors emails:

s.amaya_g@yahoo.es $(\mathrm{SAG})$

santosnoemi@uniovi.es (NSA)

amir@uniovi.es (AJMO) 


\section{Abstract}

Enzyme-immune assays are currently the methods of choice for gluten control in foods labelled as "gluten free", providing a mechanism for assessing food safety for consumption by coeliac and other allergic patients. However, their limitations, many of them associated to the reactivity of the different antibodies used and their degree of specificity, have prevented the establishment of a standardized method of analysis. We explore new methods for quantitatively determine gluten content in foods based on the use of two recently described aptamers, raised against a 33-mer peptide recognised as the immunodominant fragment from $\alpha 2$-gliadin. The assays use the target peptide immobilized onto streptavidin-coated magnetic beads in combination with a limited amount of biotin-aptamer in a competitive format, followed by streptavidin-peroxidase labelling of the aptamer that remains bound to the magnetic beads. The enzyme activity onto the beads, measured by chronoamperometry in disposable screen-printed electrodes, is inversely related to the target concentration in the test solution. We find that while the assay using the aptamer with the highest affinity towards the target (Gli 4) achieves low detection limits $(\sim 0.5 \mathrm{ppm})$ and excellent analytical performance when challenged in samples containing the intact protein, gliadin, it fails in detecting the peptide in solution. This problem is circumvented by employing another aptamer (Gli 1), the most abundant one in the SELEX pool, as a receptor. The proposed assays allow the convenient detection of the allergen in different kind of food samples, including heat-treated and hydrolysed ones. The obtained results correlate with those of commercially available antibody-based assays, providing an alternative for ensuring the safety and quality of nominally gluten-free foods.

Keywords: Aptamer, Coeliac disease, Electrochemical detection, Gliadin analysis, Gluten, 33-mer peptide. 


\section{Introduction}

Gluten detection is an outstanding problem because of its relation with coeliac disease (CD) and gluten-related allergies or intolerances. CD is one of the most prevalent autoimmune diseases affecting $1 \%$ of population and is related to genetic factors and triggered by the ingestion of gluten [1]. The only treatment for CD is the strict following of a lifelong gluten free diet. Because of the seriousness of the CD and its prevalence, EU legislation enforces the labelling of food that may contain glutencontaining cereals, and allows to label as "gluten free" products those containing less than $20 \mathrm{ppm}$ of gluten [2]. However, there is not universal agreement on what the term "gluten free" means. For example, Spanish Federation of CD patients Associations (FACE) stablishes a "Gluten Free Certification", which assures that the product contains less than $10 \mathrm{ppm}$ of gluten. But there are especially sensitive patients who can develop symptomatology after the ingestion of minimal amounts of gluten that makes those limits insufficient. The lowering of the existent limits is being frustrated by the need for more sensitive and reliable gluten detection methods to be applied in the food industry.

The development of gluten detection methods has to confront some challenges because of the nature of the analytical problem. First, the lack of a clearly defined chemical target, as gluten is the popular name given to major storage proteins of certain dietary grains. Gliadins, the alcohol soluble fraction of wheat gluten, and homologous proteins in barley, rye and possibly oats, globally termed as prolamins, are the main target in gluten analysis. Additionally, during food processing the proteins composing gluten may suffer alterations induced by thermal or enzymatic treatments. Gluten proteins have a relatively large amount of $-\mathrm{SH}$ containing amino acids. These residues form intrachain S-S bonds that suffer different changes depending on the thermal food 
processing. Breaking of the S-S intrachain bonds and formation of new ones between different chains originates a polymeric structure with low solubility, avoiding quantitative extraction of the proteins and affecting its further analysis [3]. The most common sample treatment involves extraction of gluten prolamins using a $60 \%$ ethanol solution. This extraction is not capable of fully dissolving gluten in heat processed foods [4]. In order to overcome this problem different extraction solutions have been developed, incorporating a reducing reagent, for breaking interchain S-S bonds, and caotropic agents, to solubilize gluten proteins in the extraction solution $[4,5]$. The most used extraction mixture, called "cocktail" is composed of 2-mercaptoethanol and guanidine hydrochloride [5]. Another important alteration of the proteins occurs when food processing involves treatments in which gluten can be hydrolysed. In the production of starch and syrup and in brewery enzymatic processing breaks down the proteins into small peptides that are also toxic for $\mathrm{CD}$ patients [6-8]. These immunotoxic small peptides must also be detected to estimate the toxicity of these products for celiac patients.

Enzyme-linked immunosorbent assays (ELISA) are the currently accepted methods for gluten determination in foods. Several antibodies targeting different fragments of gluten proteins are employed [9-12]. Despite their many positive characteristics, the traditional sandwich ELISA is not suitable for quantifying gluten in hydrolysed foods because it requires the presence of at least two epitopes in the target molecule, which is unlikely in the fragments obtained after hydrolysis. To overcome this drawback, competitive immunoassays have been developed based on the R5 antibody and using as calibration standard gliadin [4] or a mixture of whole protein and hydrolysed fragments [13] or on the G12 antibody and tracing the calibration curve using whole gliadin [11]. However, neither the sandwich assays, not the competitive ones are fully compatible with the 
cocktail extraction solution because their components may denature the protein receptor [14]. A non-protein receptor for gliadin would thus contribute to the improvement of gluten detection methods.

With the aim of solving this problem, we have recently obtained a panel of aptamers for specific binding to gliadin [15]. These non-protein receptors, obtained against one of the main immunogenic gluten peptides known as 33-mer [7], are able to bind not only the peptide used as target for selection but also the whole protein and homologous ones in rye, barley and oats, suggesting they might serve as viable receptors for the detection of gluten in foods at concentrations below the 20 ppm threshold proposed by the Codex Alimentarius Commission. Here, we expand this approach developing and validating two electrochemical competitive assays on magnetic particles for the determination of gluten. These assays rely on the use of two of the selected aptamers i.e. Gli 4, the ligand with the highest affinity towards gliadin, and Gli 1 the most abundant in the selection pool, whose binding to the peptide may be kinetically favoured. Their analytical performance is comparatively evaluated and validated against gliadin-ELISA kits. Both assays are complementary, proving to be reliable tools for sensitive detection of gluten in a wide variety of foods, including heat-treated and hydrolysed ones.

\section{Materials and methods}

Reagents

DNA aptamers $\left(5^{\prime} \rightarrow 3^{\prime}\right)$, both labelled in $5^{\prime}$ with biotin, Gli 4: (CCAGTCTCCCGTTTACCGCGCCTACACATGTCTGAATGCC) and Gli 1: (CTAGGCGAAATATAGCTACAACTGTCTGAAGGCACCCAAT), which are tagged with biotin at its 5 '-terminus, were obtained from Integrated DNA Technologies (IDT, Leuven, Belgium). 
Unmodified (LQLQPFPQPQLPYPQPQLPYPQPQLPYPQPQPF; 33-mer) and biotinylated (LQLQPFPQPQLPYPQPQLPYPQPQLPYPQPQPFHHHHHH-lysineBiotin; Biotin-33-mer) peptides and QQPFP were purchased from Biomedal (Sevilla, Spain).

Streptavidin modified magnetic beads with a binding capacity of $4 \mathrm{nmol} \mathrm{mL} L^{-1}$ of free biotin (Dynabeads ${ }^{\circledR}$ MyOne ${ }^{\mathrm{TM}}$ streptavidin $\mathrm{C} 1,1 \mu \mathrm{m} \Phi, 10 \mathrm{mg} \mathrm{mL}^{-1}$ ) were provided by Life Technologies (Madrid, Spain). Gliadin standard solutions were prepared using the gliadin standard provided by the Working Group on Prolamin Analysis (PWG) and acquired to R-Biopharm. Streptavidin-Peroxidase conjugate (Str-HRP 2,176 units mg ${ }^{-1}$ peroxidase activity) was obtained from Thermo Fisher (Madrid, Spain). Reagents for buffer preparation, guanidinium hydrochloride, mercaptoethanol, polyvinylpyrrolidone, fish gelatine and enzymatic substrate 3,3',5,5'-tetramethylbenzidine (TMB) liquid substrate system for ELISA were purchased from Sigma-Aldrich. Solutions were prepared using MilliQ purified water.

\section{Procedures}

Modification of streptavidin coated magnetic beads: An aliquot of $50 \mu \mathrm{L}$ of the streptavidin-magnetic beads stock solution was washed twice with BLmod (1 mL PBS $+0.01 \%$ Tween-20) for $2 \mathrm{~min}$ and then resuspended in $1 \mathrm{~mL}$ of $2 \mu \mathrm{M}$ biotinylated 33mer in BLmod. The tube was incubated for $30 \mathrm{~min}$ at $30{ }^{\circ} \mathrm{C}$ in a Thermomixer (Eppendorf Ibérica, Spain) under continuous shaking. After that, the beads were washed twice in BLmod and blocked with $500 \mu \mathrm{M}$ biotin in BLmod for 30 min. After two new washing steps, they were reconstituted in $500 \mu \mathrm{L}$ BS (50 mM TRIS pH 7.4+0.25 M $\mathrm{NaCl}+5 \mathrm{mM} \mathrm{MgCl}_{2}$ ) and used within the same day.

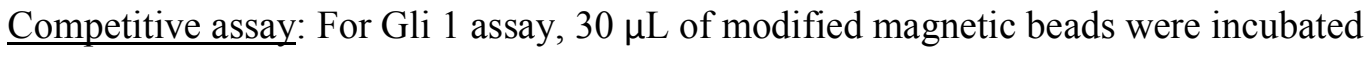
in $500 \mu \mathrm{L}$ of BS with $250 \mathrm{nM}$ of biotinylated aptamer and selected amounts of 
calibration standard (or $10 \mu \mathrm{L}$ of extracted sample) for $30 \mathrm{~min}$ at $30^{\circ} \mathrm{C}$ in Thermomixer under shaking. After that, the beads were washed twice with BSL (50 mM TRIS pH 7.4+0.25 M NaCl+5 mM MgCl $2+0.01 \%$ Tween-20), and incubated with an excess of enzymatic conjugate $\left(2.5 \mu \mathrm{g} \mathrm{mL}^{-1} \mathrm{Str}-\mathrm{HRP}_{2}\right)$ in $500 \mu \mathrm{L}$ of BSL for $30 \mathrm{~min}$ at $30{ }^{\circ} \mathrm{C}$ under shaking. Finally, the beads were washed twice with BSL, once with BS and resuspended in $30 \mu \mathrm{L}$ of BS.

For Gli 4 assay, $10 \mu \mathrm{L}$ of modified magnetic beads were incubated in $1 \mathrm{~mL}$ of BS with $250 \mathrm{nM}$ of biotinylated aptamer and selected amounts of calibration standard (or $20 \mu \mathrm{L}$ of extracted sample) for $30 \mathrm{~min}$ at $30{ }^{\circ} \mathrm{C}$ in Thermomixer under shaking. After that, the beads were washed twice with BSL, and incubated with an excess of enzymatic conjugate $\left(2.5 \mu \mathrm{g} \mathrm{mL}^{-1} \mathrm{Str}-\mathrm{HRP}_{2}\right)$ in $1 \mathrm{~mL}$ of BSL for $30 \mathrm{~min}$ at $30{ }^{\circ} \mathrm{C}$ under shaking. Finally, the beads were washed twice with BSL, once with BS and resuspended in 10 $\mu \mathrm{L}$ of BS.

Amperometric measurement: The resuspended beads $(10 \mu \mathrm{L})$ were captured on screen printed carbon electrodes (Dropsens, Oviedo, Spain) placing a magnet under the working electrode, and the electrochemical cell was covered with $40 \mu \mathrm{L}$ of 3,3',5,5'tetramethylbenzidine $+\mathrm{H}_{2} \mathrm{O}_{2}$ substrate. The enzymatic reaction was developed for $30 \mathrm{~s}$ and the enzymatically obtained product measured by chronoamperometry at $0 \mathrm{~V}$ using a $\mu$-AutoLab type II potentiostat (Ecochemie, The Netherlands).

Extractions: For the extraction of flours and no heat-processed foods, $0.8 \mathrm{~g}$ of flour or homogenised food sample was placed in a $15 \mathrm{~mL}$ Falcon tube and washed with an aqueous solution of $2 \mathrm{M} \mathrm{NaCl}$. After 20 minutes of shaking at RT, the tube was centrifuged in a Heraeus Multifuge 1L-R (ThermoScientific) for $15 \mathrm{~min}$ at $7500 \mathrm{~g}$ and the supernatant was discarded. Prolamins were extracted twice with ethanol $60 \%$ solution. For this purpose $4 \mathrm{~mL}$ of ethanol solution were added to the tube and the 
mixture was incubated at RT during $20 \mathrm{~min}$ and then centrifuged for $15 \mathrm{~min}$ at $7500 \mathrm{~g}$, and both supernatants were combined.

Some food samples were also extracted as follows: $0.25 \mathrm{~g}$ of ground sample was mixed with $2 \mathrm{~mL}$ of cocktail solution ( $250 \mathrm{mM}$ mercaptoethanol, $2 \mathrm{mM}$ guanidine in $0.1 \times$ PBS). The suspension was incubated in an oven at $50{ }^{\circ} \mathrm{C}$ for $40 \mathrm{~min}$. Once at room temperature, $3 \mathrm{~mL}$ of ethanol were added and extraction in a shaker was extended for 1 hour. Finally the samples were centrifuged for $30 \mathrm{~min}$ at $2500 \mathrm{~g}$, and the supernatant was used in the analysis. The sample containing chocolate was extracted in the presence of $0.25 \mathrm{~g}$ of gelatin and $0.1 \mathrm{~g}$ of polyvinypyrrolidone, which were added to $0.25 \mathrm{~g}$ of ground sample before the extraction.

\section{Results and discussion}

We chose a competitive assay format, well suited to detect both intact protein and small protein fragments, using two previously selected aptamers targeting the immunotoxic a2-gliadin fragment, 33-mer [15]. Magnetic microparticles are employed as support for the sensing phase to take advantage of the efficient magnetic separation offered by this platform, which facilitates subsequent exhaustive washing steps thus minimizing major problems associated with non-specific interactions. The preparation of the sensing phase is very simple. A commercially available 33-mer, modified at its carboxy-terminus with a biotin, is immobilized onto the surface of streptavidin-modified magnetic particles and then the unoccupied sites of streptavidin are blocked with biotin. The analytical assay we developed using this platform comprises the following steps (Figure 1): first, the sample and the biotin-labelled aptamer are incubated with a fixed amount of the modified magnetic beads. In this step, the analyte from the test solution competes with the immobilized peptide for a limited amount of aptamer. As a result, part of the biotin- 
aptamer is specifically captured and separated from the sample after applying an external magnetic field. In order to detect the bound aptamer, particles are incubated in a second step with a streptavidin-peroxidase conjugate containing two molecules of enzyme per streptavidin as reporter molecule. Finally, the enzyme activity on the surface is electrochemically quantified by magnetically entrapping the modified beads onto a screen-printed carbon electrode. After the addition of tetramethylbenzidine and hydrogen peroxide we measured by chronomaperometry the reduction of the product enzymatically produced. The higher the concentration of gliadin in the sample is the lower the reduction current we obtain.

\section{Figure 1.}

\subsection{Assay Optimization}

To obtain optimal conditions for the competitive assay, the concentration of biotinaptamer was first selected, fixing the amount of magnetic particles modified with the peptide in $0.06 \mathrm{mg} \mathrm{mL}^{-1}$. In this study, different concentrations of the aptamers in the range $0.5 \mathrm{nM}-2 \mu \mathrm{M}$ were tested without protein or peptide in solution. This analysis produces typical binding curves for both aptamers (Figure 2). $250 \mathrm{nM}$ of aptamer, the concentration that yield around $50 \%$ of the maximum obtained signal, was selected for competition. In the absence of the aptamers, we observe only a small reduction current $(0.4 \pm 0.1 \mu \mathrm{A})$, which confirmed that the contribution of the nonspecific interaction of Str-HRP $\mathrm{H}_{2}$ conjugate is not significant. The assay also gives negligible responses when it is performed using a randomized biotinylated DNA library at a $250 \mathrm{nM}$ concentration level. Conversely, we registered a maximum signal value of $4.7 \pm 0.1 \mu \mathrm{A}$ and $3.6 \pm 0.1$ $\mu \mathrm{A}$ for Gli 4 and Gli 1, respectively at this aptamer concentration. These results are consistent with the specific interaction of both aptamers with the immobilized peptide and a higher affinity for the aptamer Gli 4 [15]. 


\section{Figure 2}

The second variable we took into consideration is the composition of the competition buffer. To evaluate the effect of ethanol in the aptamer/peptide interaction, we performed the competitive assay in buffer containing different concentrations of this alcohol. The presence of $1.2 \%$ of ethanol, which will correspond to a 1:50 dilution of samples extracted using $60 \%$ ethanol, increases the maximum signal obtained while the blank is not affected. The improved signal amplitude at $1.2 \%$ ethanol can be explained given the apolar nature of the peptide modifying the surface of the beads, which may cause their slight aggregation. A small amount of ethanol may act as disaggregating agent, favouring the aptamer/peptide interaction. Consistent with this, the competitive assay achieves improved signal decrease with this amount of ethanol in the buffer. At $3 \%$ of ethanol the binding of Gli 1 to the peptide decreases to about $35 \%$ of the maximum while Gli 4 interaction is less affected, which again is in agreement with the lower affinity constant for the peptide-Gli 1 reaction.

Therefore, the best performance in terms of sensitivity is obtained employing $0.06 \mathrm{mg}$ $\mathrm{mL}^{-1}$ of the modified beads and $250 \mathrm{nM}$ aptamer, in the presence of $1.2 \%$ ethanol. Upon the addition of $10 \mu \mathrm{g} \mathrm{L}^{-1}$ of PWG standard to the competition buffer in the presence of Gli 1 , a $13 \%$ of signal decrease is observed with a coefficient of variation of $6 \%$. Under the same conditions, Gli 4 gives rise to higher sensitivity with about $\underline{20} \%$ of decrease at the same concentration of PWG. We find, however, that this aptamer leads to worse reproducibility, more than $15 \%$ of $\mathrm{RSD}$ at $10 \mu \mathrm{g} \mathrm{L}^{-1}$, probably related to the fact that a higher tendency of the 33-mer-modified magnetic particles to aggregate is observed with this aptamer. To overcome this difficulty we performed the competitive assay with Gli 4 using a higher dilution of the magnetic beads during the competition i.e $0.01 \mathrm{mg}$ $\mathrm{mL}^{-1}$, while maintaining the amount of beads on the electrode surface for measurement 
$(10 \mu \mathrm{g})$. In this way sensitivity of the assay was not affected and precision was improved, with a RSD of $6 \%$ for $10 \mu \mathrm{g} \mathrm{L}^{-1}$ of PWG.

\subsection{Analytical performance}

The performance of both aptamers in competitive assays under the optimum conditions was compared using PWG gliadin or 33-mer peptide as standards. The selection of the standard in order to obtain a calibration to which refer the measurements of the samples have to be carefully done to avoid deviations in the value obtained. Most used calibration and validation standard is PWG gliadin, a material obtained after processing of 28 different cultivars of wheat [16]. We used this material as a gliadin standard to obtain the calibration curve.

In Figure 3A, the current intensities obtained after challenging the modified beads with increasing concentrations of PWG using both aptamers is depicted. As expected, aptamer Gli 4 gives rise to higher currents than aptamer Gli 1 as a result of the difference in affinity.

Data were fitted to a four parameters logistic (equation 1)

$$
y=A+\frac{(B-A)}{1+\left(\frac{x}{\mathrm{EC}_{50}}\right)^{p}}
$$

where $\mathrm{A}$ is the response at an infinite concentration of analyte, $\mathrm{B}$ is the response at a zero concentration of analyte, $\mathrm{EC}_{50}$ is the concentration of analyte that corresponds to the $50 \%$ of the maximum signal and $\mathrm{p}$ is the Hill slope that represents the slope at the inflexion point of the sigmoidal curve. Due to the low solubility of gliadin in aqueous solution concentrations higher than $1 \mu \mathrm{g} \mathrm{L}{ }^{-1}$ were not assayed, which precluded the observation of the complete sigmoidal curve. The best fitting were obtained fixing A parameter to zero and the equations are the following: 
$\left.\mathrm{I}(\mu \mathrm{A})=(3.60) /\left(1+\left(\left[P W G\left(\mu g L^{-1}\right)\right]\right) / 721\right)^{0.5}\right) ; \mathrm{r}=0.980$ for Gli 1 and

$\mathrm{I}(\mu \mathrm{A})=(5.17) /\left(1+\left(\left[P W G\left(\mu g L^{-1}\right)\right] / 273\right)^{0.6}\right) ; \mathrm{r}=0.997$ for Gli 4.

The limit of detection of each assay was calculated as the concentration that gives the $95 \%$ of the maximum signal and corresponds to $4.9 \mu \mathrm{g} \mathrm{L}^{-1}$ of gliadin when using Gli 1 as recognition element and $0.5 \mu \mathrm{g} \mathrm{L}^{-1}$ of gliadin when using Gli 4. Taking into account the sample extraction, the dilution of the extract and the gliadin to gluten ratio, the limit of detection in real samples can be calculated in order to verify whether the methods meet the requirements to evaluate the accomplishment of the EU legislation. The overall sample dilution is 1:500 and the content of gliadin in gluten is considered as $50 \%$, [17] though values ranging from $32 \%$ to $67 \%$ have been found [18], so the limit of detection expressed in gluten for each assay is $4.9 \mathrm{ppm}$ and $0.5 \mathrm{ppm}$ for Gli 1 and Gli 4 , respectively. Those values are below the limits needed to check the legislation accomplishment and are similar or slightly lower than competitive immunoassays even those currently marketed [4,11,19-21].

\section{Figure 3}

The repeatability of the assays calculated as the coefficient of variation at 1 and $10 \mu \mathrm{g}$ $\mathrm{L}^{-1}$ of gliadin concentration were 7 and $8 \%$, respectively for Gli 1 aptamer and 9 and 6 $\%$, respectively for Gli 4 . The inter assay reproducibility, calculated with the signal obtained for $10 \mu \mathrm{g} \mathrm{L}^{-1}$ in three different days is $9.5 \%$ for Gli 1 assay and $6 \%$ for Gli 4 assay.

Competitive assays are specifically designed for hydrolysed samples where the proteins are digested to small peptides containing a single epitope for the antibody. The competitive format of R5 antibody uses a peptide fragment (QQPFP) as a standard even though the equivalence between peptide fragments and the intact protein is lacking [13]. This precludes the conversion of the results into gluten content as required in the 
legislation [17]. On the contrary, the competitive G12 assay uses the intact protein [11]. We have previously found a correlation between Sigma gliadin and 33-mer using G12 antibody in an electrochemical competitive immunoassay [20]. Therefore, the feasibility of using 33-mer peptide as a standard for the competitive apta-assay was studied. In Figure 3B, the response of Gli 1-based method to increasing concentrations of 33-mer is shown and compared with the calibration plot using PWG both expressed in nM. It is apparent that the aptamer recognizes the peptide but at much larger concentrations than the intact protein, which indicates that PWG contains several binding sites in its structure. However, the number of those "aptatopes" would be very high, about 200, which seems unrealistic. In our previous work two binding sites for the antibody G12 were found in each gliadin standard, which is reasonable. Recently, we have found that Gli 1 exhibits positive cooperativity when binding to PWG, which can explain the apparent higher affinity towards the intact protein even taking into consideration the presence of several binding sites [22].

On the contrary, proper calibration plots using Gli 4 aptamer as recognition element and 33-mer peptide as standard were not obtained. This fact is attributed to microscopic aggregation of the beads in presence of this aptamer. Therefore, Gli1 aptamer was selected as the receptor for subsequent testing of hydrolysed samples.

The response of Gli 1 aptamer to the recognition epitope of the official R5 method, that is, the pentapeptide QQPFP [23] was also tested. This specific sequence is not present in the immunodominat 33-mer peptide used for aptamer selection but it is present in wheat, rye and barley prolamins. The aptamer was able to recognize this peptide but at much higher concentrations than 33-mer (above $1 \mu \mathrm{M}$ ), which suggests a much lower affinity accordingly to its absence in the selection target. 


\subsection{Cross-reactivity against other cereals and grains}

Not only wheat proteins are toxic for coeliac disease patients, prolamins from barley and rye have almost the same toxicity. However, the toxicity of oat for coeliac patients is still controversial [24]([25] and citation therein), so oat prolamins also have to be evaluated towards the quantification of the toxicity in food products. For this reason it is necessary to evaluate the response of the competitive assays using Gli 1 and Gli 4 aptamers against prolamins from other toxic cereals and the selectivity against not-CDtriggering cereals and grains. Because of the unavailability of prolamin standards or reference materials from other grains, the ethanol-soluble fraction was extracted from each grain flour. After the extraction, the total protein present in solution was quantified by the Bradford method using PWG as standard, obtaining a content in prolamin for each extract as follows: wheat $5.4 \mathrm{mg} \mathrm{mL}^{-1}$, rye $4.6 \mathrm{mg} \mathrm{mL}^{-1}$, barley $5.2 \mathrm{mg} \mathrm{mL}^{-1}$ and oat $4.7 \mathrm{mg} \mathrm{mL}^{-1}$. All the extracts were diluted at different levels to obtain the desired protein concentration in the competition buffer. As it can be seen in Figure $\mathbf{4}$ both assays with Gli 1 and Gli 4, recognise gliadins (wheat), hordeins (barley) and secalins (rye) in a similar extension within the experimental error. However, the response to avenins (oat) is different. Gli 1 aptamer is not able to bind oat proteins while Gli 4 aptamer recognises avenins but with less affinity than the rest of prolamins from CD toxic cereals. This result is interesting because the antibodies G12 and A1, also raised against the 33-mer peptide, weakly binds to avenins although 33-mer is not present in their sequence [26]. The sensitivity order to prolamins was, however, different: hordenins $\approx$ gliadins $>$ secalins $>>$ avenin for $\mathrm{G} 12$ and hordeins $\approx$ rye $>$ gliadin $>>$ avenins for the aptamers. In our case, differences between hordeins, gliadins and secalins are less pronounced in both cases. The official R5 method does not respond to the controversial oat prolamins [10]. 


\section{Figure 4}

It is also important to ensure the non-response of the developed method against proteins from non-toxic flours such as soya, maize and rice often used as substitutes of toxic cereals to elaborate CD-safe food. To evaluate the cross-reactivity, the response to increasing concentrations of proteins extracted from soya, maize and rice flours were assayed. In all concentration range, the analytical responses expressed as current percentage of the maximum current obtained in the absence of protein were around $100 \%$. Specifically, percentages obtained with Gli 1 assay were: soya $112 \pm 11 \%$ maize $135 \pm 26 \%$ and rice $112 \pm 9 \%$. For the Gli 4 assay were: soya $125 \pm 37 \%$, maize $121 \pm 36$ $\%$ and rice $113 \pm 25 \%$. According to this, aptamers do not cross react with non-toxic proteins.

\subsection{Application of the competitive assays to food samples}

The competitive methods developed are sensitive and selective enough to be applied to gluten determination in gluten free labelled foods in order to evaluate the compliance with the law and to provide more information to the consumer. To do this, we tested samples provided by two external laboratories. All of them had unknown gluten content. The samples provided by Laboratory I were divided, according to the information given by the company, in two groups: non-hydrolysed (Table 1) to be quantified by the Gli 4 assay that is more sensitive, and hydrolysed samples (Table 2) to be quantified by Gli 1 assay, the peptide- responsive one. Liquid samples were just diluted with $60 \%$ ethanol and solid samples were extracted with the conventional extraction procedure using $60 \%$ ethanol, which is the method recommended by the commercial kit based on G12, the antibody used by the company for comparison. Samples are considered as positive when the gluten $\underline{\text { content is above the limit of quantification of the method used in each case, even in cases }}$ where samples meet gluten free specifications (less than $20 \mathrm{ppm}$ gluten). 
Samples identified as positive with the reference methods are in general positive with our method. There are two apparent exceptions, both liquid non-hydrolysed samples (liquids C and $\mathrm{H})$. These are gluten free samples that were spiked with gluten by the external laboratory in a blind assay. The recovery values we found for these samples are close $100 \%$ even in the case of sample $C$, spiked with a gluten concentration very near to the limit of quantification of our method. So we can conclude that our method does not present false negative results. Only one out of the 5 liquid non-hydrolysed samples analysed (liquid A) was negative by the G12 immunoassay. In this sample our method detected gluten but with a content below the $20 \mathrm{ppm}$ threshold level. This difference may be due to the improved sensitivity of our method with respect to G12. Gliadin levels measured in the solid nonhydrolysed samples were comparable with levels detected by G12 assay in $50 \%$ of samples (3 out of 6). Both methods showed non-detectable gluten in a rice sample. In general, our method detects higher gluten content than did the G12 kit. Interestingly, the three discordant samples are negative by G12-assay, and positive by our method. These differences can be explained by variations in the extracted target compounds detected by the two assays.

Attending to the results for hydrolysed samples (Gli 1 assay, Table 2), there is a good correlation between the results provided by the external analysis and those obtained using the competitive assay developed in this work. This correlation demonstrates the applicability of the competitive assay based on the aptamer Gli 1 to quantify gluten in hydrolysed samples. Only a false positive result was obtained, corresponding to a sample of a gluten free beer. It is accepted that samples where the gluten content differ most are the hydrolysed ones because the value obtained strongly depends on the target sequence detected [27]. In a previous study, hordein content in gluten was comparatively assessed using ELISA and MS [28]. This study reveals significant differences between both methods, showing that $10 \%$ of the tested beers give ELISA gluten contents below the limit 
of quantification but near average hordein content by MS. Our assay, using an aptamer

that detects hordeins [15], could be an alternative for this kind of samples.

Solid samples provided by Laboratory II (Table 3) were extracted alternatively with the conventional $60 \%$ aqueous ethanol extraction method and with cocktail solution to evaluate the influence of reducing and denaturing agents on our method. The results were compared with values obtained with the official method (R5) provided by the company after carrying out the analysis with the Gli 4 competitive method and with an independent analysis performed by a certified Spanish company for gluten analysis (Laboratory III). Most of the values obtained with R5 antibody were comparable with those obtained with our method after ethanol extraction except for cappuccino, where a false positive result is observed. Again, this is probably due to the increased sensitivity of our method. The influence of the cocktail solution on the aptamer-based competitive method was studied. In general higher results were obtained with the cocktail solution, probably because a larger yield of the extraction. The exception was the sample containing chocolate, even though PVP and fish gelatin were used to assist the extraction. It is remarkable the discrepancy between the analysis using the same procedure, which is an indication of the difficulty of such samples. Additional discrepancies are observed in corn flakes samples which would led to labelling as gluten free according to one of the laboratories but not to the other. Our results with ethanol extraction are in agreement with laboratory II and are closer to laboratory III after cocktail extraction for one of them. Therefore, it can be concluded that the alteration of the protein conformation during the extraction procedure does not significantly affect its recognition by the aptamer (no false negative detected) and the cocktail solution is compatible with our aptamer-based competitive method unlike competitive immunoassays. 


\section{Conclusions}

The combination of magnetic beads and aptamers as receptors has proved to be an attractive method for the sensitive quantification of gluten, with a detection limit of 0.5 ppm in the case where the aptamer (Gli 4) with the highest binding affinity to the protein is employed, and $4.9 \mathrm{ppm}$ when using Gli 1, the most abundant aptamer. The assays can quantify gluten in food samples below the legally established limits for the labelling of "gluten free" products. Gli 4-based method is compatible with cocktail extraction method, allowing the quantification of gluten in heated foods. The assay using Gli 1 aptamer can quantify gluten in hydrolysed samples. Both methods are complementary and can be valuable tools in the determination of gluten in foods intended for coeliac patients.

\section{Acknowledgements}

SAG thanks the Spanish Government for a predoctoral FPI grant. This work was financed by Spanish Government Project CTQ2012-31157, and the European Regional Development Fund. 


\section{TABLES}

Table 1: Samples extracted with ethanol $60 \%$ and analysed with Gli4 aptamer. They were compared with a G12 method carried out by the external laboratory

\begin{tabular}{ccc}
\hline Sample & $\begin{array}{c}\text { Gli } 4 \text { method } \\
\text { (ppm gluten) }\end{array}$ & $\begin{array}{c}\text { External Laboratory I } \\
\text { (ppm gluten) }\end{array}$ \\
\hline Quillet flour & $16 \pm 2$ & 15 \\
Quinoa & $76 \pm 24$ & 40 \\
Maize flour & $35 \pm 20$ & Negative \\
Chamtor sample & $36 \pm 25$ & Negative \\
Almond flour & $116 \pm 65$ & Negative \\
\hline Liquid sample A & $12 \pm 1$ & Negative \\
Liquid sample B & $30 \pm 13$ & Negative \\
Liquid sample C & $1 \pm 0.6$ & Positive \\
Liquid sample G & $35 \pm 7$ & Positive \\
Liquid sample H & $16 \pm 5$ & Positive \\
\hline
\end{tabular}


Table 2: Analysis of liquid hydrolysed samples by the Gli 1 based competitive method and comparison with the values provided by the external laboratory.

\begin{tabular}{ccc}
\hline Sample & $\begin{array}{c}\text { Competitive Gli } 1 \\
\text { (ppm gluten) }\end{array}$ & External \\
& Laboratory I \\
\hline Wheat beer (Paulaner) & $224 \pm 5$ & Positive \\
Liquid sample D & $46 \pm 6$ & Dubious \\
Liquid sample E & $92 \pm 29$ & Positive \\
Spanish beer (Cruzcampo) & $130 \pm 27$ & Positive \\
Liquid sample F & $130 \pm 28$ & Positive \\
Daura Beer (gluten free) & $113 \pm 36$ & Negative \\
\hline
\end{tabular}


Table 3: Samples analysed with the assay using Gli 4 aptamer after two different extraction protocols and compared with R5 method carried out by two independent laboratories.

\begin{tabular}{ccccc}
\hline Sample & ethanol extraction & cocktail & Lab II & Lab III \\
& (ppm gluten) & extraction & $(\mathrm{ppm}$ & (ppm \\
& & (ppm gluten) & gluten) & gluten) \\
\hline Cake & $>100$ & $>100$ & 78 & $>80$ \\
Fixamyl & $8 \pm 3$ & 30 & 7 & $13.3 \pm 1.1$ \\
Capuccino & $23 \pm 3$ & 50 & $<5$ & $<5$ \\
Rolled oats & $63 \pm 9$ & $97 \pm 9$ & 77 & $>80$ \\
Corn flakes 2 & 34 & $58 \pm 4$ & 38 & $18.1 \pm 1.3$ \\
Dessert Chocolate & 11 & $<$ LD & 13 & $<5$ \\
Fit snack & $81 \pm 8$ & 90 & 77 & $>80$ \\
Vanilla cream & $<6$ & $<$ LD & $<5$ & $<5$ \\
Corn flakes 1 & 13 & $34 \pm 7$ & 17 & $30.8 \pm 1.9$ \\
Panna Cotta & $6 \pm 1$ & $<$ LD & $<5$ & $<5$ \\
\hline
\end{tabular}




\section{CAPTION FOR THE FIGURES}

Figure 1: Schematic representation of the competitive aptamer-based assay for gliadin determination.

Figure 2: Binding curves of aptamers Gli $4 \underline{(\bullet, \text { dashed line) }}$ and Gli 1 ( $\square$, solid line) to 33-mer-peptide immobilized onto magnetic beads through biotin-estreptavidin interaction.

Figure 3: Calibration curves for the competitive assay: (A) using Gli $\underline{4}(\cdot$, dashed line) and Gli $\underline{1}$ ( $\square$, solid line) aptamers with PWG gliadin as a standard (B) using Gli 1 aptamer with PWG gliadin ( $\square$, solid line) and 33-mer peptide $(\bullet$, dashed line) as standards.

Figure 4: Response of the competitive assay expressed as percentage of the maximum signal obtained in the absence of protein to different toxic prolamins from wheat $(\downarrow$ red

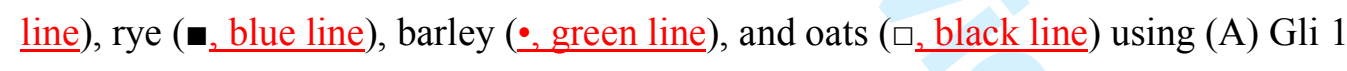
and (B) Gli 4 aptamers. 


\section{REFERENCES}

1. Rostom A, Murray JA, Kagnoff MF (2006) American Gastroenterological Association (AGA) institute technical review on the diagnosis and management of celiac disease. Gastroenterology 131 (6):1981-2002.

2. Commission Implementing Regulation (EU) 828/2014 (2014). L228:5-8.

3. Schofield JD, Bottomley RC, Timms MF, Booth MR (1983) The effect of heat on wheat gluten and the involvement of sulfhydryl-disulfide interchange reactions. Journal of Cereal Science 1 (4):241-253.

4. Mena M, Lombardia M, Hernando A, Mendez E, Albar J (2012) Comprehensive analysis of gluten in processed foods using a new extraction method and a competitive ELISA based on the R5 antibody. Talanta 91:33-40.

5. Garcia E, Llorente M, Hernando A, Kieffer R, Wieser H, Mendez E (2005) Development of a general procedure for complete extraction of gliadins for heat processed and unheated foods. Eur J Gastroenterol Hepatol 17 (5):529-539.

6. Tye-Din JA, Stewart JA, Dromey JA, Beissbarth T, van Heel DA, Tatham A, Henderson K, Mannering SI, Gianfrani C, Jewell DP, Hill AVS, McCluskey J, Rossjohn J, Anderson RP (2010) Comprehensive, quantitative mapping of T cell epitopes in gluten in celiac disease. Sci Transl Med 2 (41):41-51.

7. Shan L, Molberg Ø, Parrot I, Hausch F, Filiz F, Gray GM, Sollid LM, Khosla C (2002) Structural basis for gluten intolerance in celiac sprue. Science 297 (5590):22752279. 


\author{
8. Anderson RP, Degano P, Godkin AJ, Jewell DP, Hill AVS (2000) In vivo antigen \\ challenge in celiac disease identifies a single transglutaminase-modified peptide as the \\ dominant A-gliadin T-cell epitope. Nat Med 6 (3):337-342.
}

9. Skerrit JH, Hill AS (1990) Monoclonal-antibody sandwich enzyme immunoassays for determination of gluten in foods. J Agric Food Chem 38 (8):1771-1778.

10. Valdes I, Garcia E, Llorente M, Mendez E (2003) Innovative approach to low-level gluten determination in foods using a novel sandwich enzyme-linked immunosorbent assay protocol. Eur J Gastroenterol Hepatol 15 (5):465-474.

11. Moron B, Cebolla A, Manyani H, Alvarez-Maqueda M, Megias M, Thomas MdC, Lopez MC, Sousa C (2008) Sensitive detection of cereal fractions that are toxic to celiac disease patients by using monoclonal antibodies to a main immunogenic wheat peptide. Am J Clin Nutr 87 (2):405-414.

12. Spaenij-Dekking EHA, Kooy-Winkelaar EMC, Nieuwenhuizen WF, Drijfhout JW, Koning F (2004) A novel and sensitive method for the detection of $\mathrm{T}$ cell stimulatory epitopes of alpha/beta- and gamma-gliadin. Gut 53 (9):1267-1273.

13. Haas-Lauterbach S, Immer U, Richter M, Koehler P (2012) Gluten Fragment Detection with a Competitive ELISA. J AOAC Int 95 (2):377-381.

14. Dona VV, Fossati CA, Chirdo FG (2008) Interference of denaturing and reducing agents on the antigen/antibody interaction. Impact on the performance of quantitative immunoassays in gliadin analysis. Eur Food Res Technol 226 (3):591-602. 
15. Amaya-González S, de-los-Santos-Álvarez N, Miranda-Ordieres AJ, Jesus LoboCastañón M (2014) Aptamer binding to celiac disease-triggering hydrophobic proteins: a sensitive gluten detection approach. Anal Chem 86 (5):2733-2739.

16. van Eckert R, Berghofer E, Ciclitira P, Chirdo F, Denery-Papini S, Ellis H, Ferranti P, Goodwin P, Immer U, Mamone G, Mendez E, Mothes T, Novalin S, Osman A, Rumbo M, Stern M, Thorell L, Whim A, Wieser H (2006) Towards a new gliadin reference material-isolation and characterisation. Journal of Cereal Science 43 (3):331341.

17. Gessendorfer B, Koehler P, Wieser H (2009) Preparation and characterization of enzymatically hydrolyzed prolamins from wheat, rye, and barley as references for the immunochemical quantitation of partially hydrolyzed gluten. Anal Bioanal Chem 395 (6):1721-1728.

18. Wieser H, Koehler P (2009) Is the calculation of the gluten content by multiplying the prolamin content by a factor of 2 valid? Eur Food Res Technol 229 (1):9-13.

19. Redondo MCB, Griffin PB, Ransanz MG, Ellis HJ, Ciclitira PJ, O'Sullivan CK (2005) Monoclonal antibody-based competitive assay for the sensitive detection of coeliac disease toxic prolamins. Anal Chim Acta 551 (1-2):105-114.

20. Amaya-González S, de-los-Santos-Álvarez N, Jesus Lobo-Castañón M, MirandaOrdieres AJ, Tuñón-Blanco P (2011) Amperometric quantification of gluten in food samples using an ELISA competitive assay and flow injection analysis. Electroanalysis $23(1): 108-114$. 
21. Laube T, Kergaravat SV, Fabiano SN, Hernandez SR, Alegret S, Pividori MI (2011)

Magneto immunosensor for gliadin detection in gluten-free foodstuff: Towards food safety for celiac patients. Biosens Bioelectron 27 (1):46-52.

22. Amaya-González S, López-López L, Miranda-Castro R, de-los-Santos-Álvarez N, Miranda-Ordieres AJ, Lobo-Castañón MJ (2015) Affinity of aptamers binding 33-mer gliadin peptide and gluten proteins: Influence of immobilization and labeling tags. Anal Chim Acta In Press:http:/dx.doi.org/10.1016/j.aca.2015.1002.1053.

23. Osman AA, Uhlig HH, Valdes I, Amin M, Mendez E, Mothes T (2001) A monoclonal antibody that recognizes a potential toxic repetitive pentapeptide epitope in gliadins. Eur J Gastroenterol Hepatol 13 (10):1189-1193.

24. Fric P, Gabrovska D, Nevoral J (2011) Celiac disease, gluten-free diet, and oats. Nutr Rev 69 (2):107-115.

25. Real A, Comino I, de Lorenzo L, Merchan F, Gil-Humanes J, Gimenez MJ, Angel Lopez-Casado M, Isabel Torres M, Cebolla A, Sousa C, Barro F, Piston F (2012) Molecular and immunological characterization of gluten proteins isolated from oat cultivars that differ in toxicity for celiac disease. PLoS One 7 (12):e48365.

26. Moron B, Bethune MT, Comino I, Manyani H, Ferragud M, Lopez MC, Cebolla A, Khosla C, Sousa C (2008) Toward the assessment of food toxicity for celiac patients: characterization of monoclonal antibodies to a main immunogenic gluten peptide. PLoS One 3 (5):e2294.

27. Real A, Comino I, de Lourdes Moreno M, Angel Lopez-Casado M, Lorite P, Isabel Torres M, Cebolla A, Sousa C (2014) Identification and in vitro reactivity of celiac immunoactive peptides in an apparent gluten-free beer. PLoS One 9 (6):e100917. 
28. Tanner GJ, Colgrave ML, Blundell MJ, Goswami HP, Howit CA (2013) Measuring

hordein (gluten) in beer - A comparison of ELISA and Mass Spectrometry. PLoS One

(8) e56452.

10

11

12

13

14

15

16

17

18

19

20

21

22

23

24

25

26

27

28

29

30

31

32

33

34

35

36

37

38

39

40

41

42

43

44

45

46

47

48

49

50

51

52

53

54

55

56

57

58

59

60 


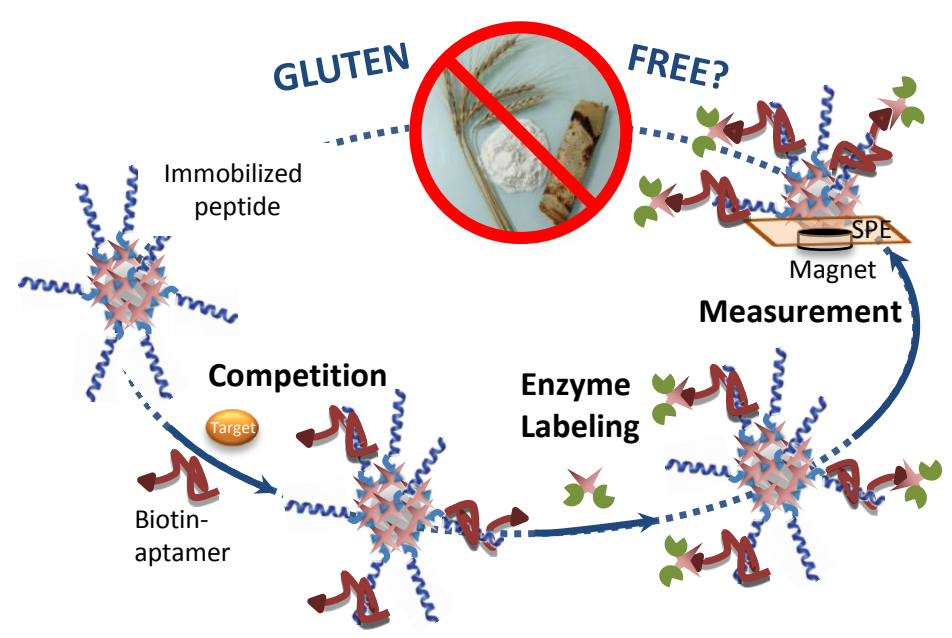




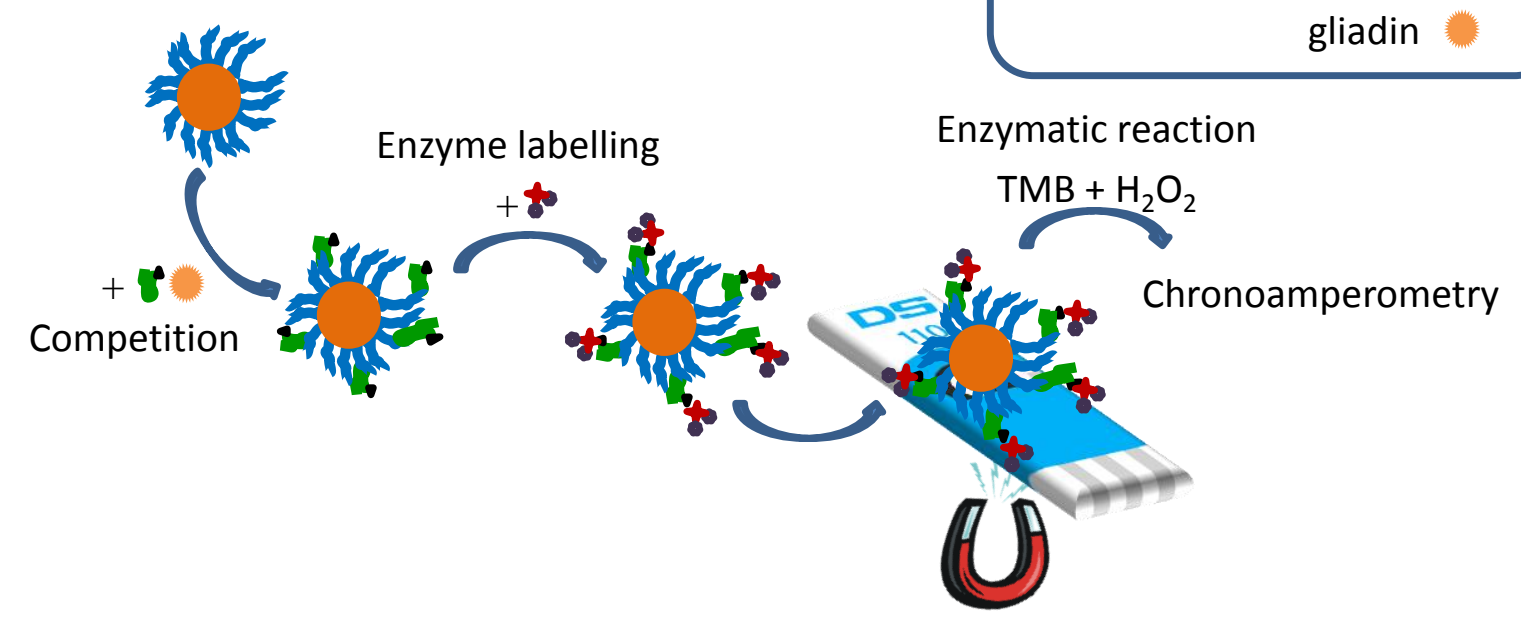

\section{3-mer peptide}

Biotinilated aptamer

Str-POD Conjugate gliadin 
1

2

3

4

5

6

7

8

9

10

11

12

13

14

15

16

17

18

19

20

21

22

23

24

25

26

27

28

29

30

31

32

33

34

35

36

37

38

39

40

41

42

43

44

45

46

47

48

49

50

51

52

53

54

55

56

57

Figure 2

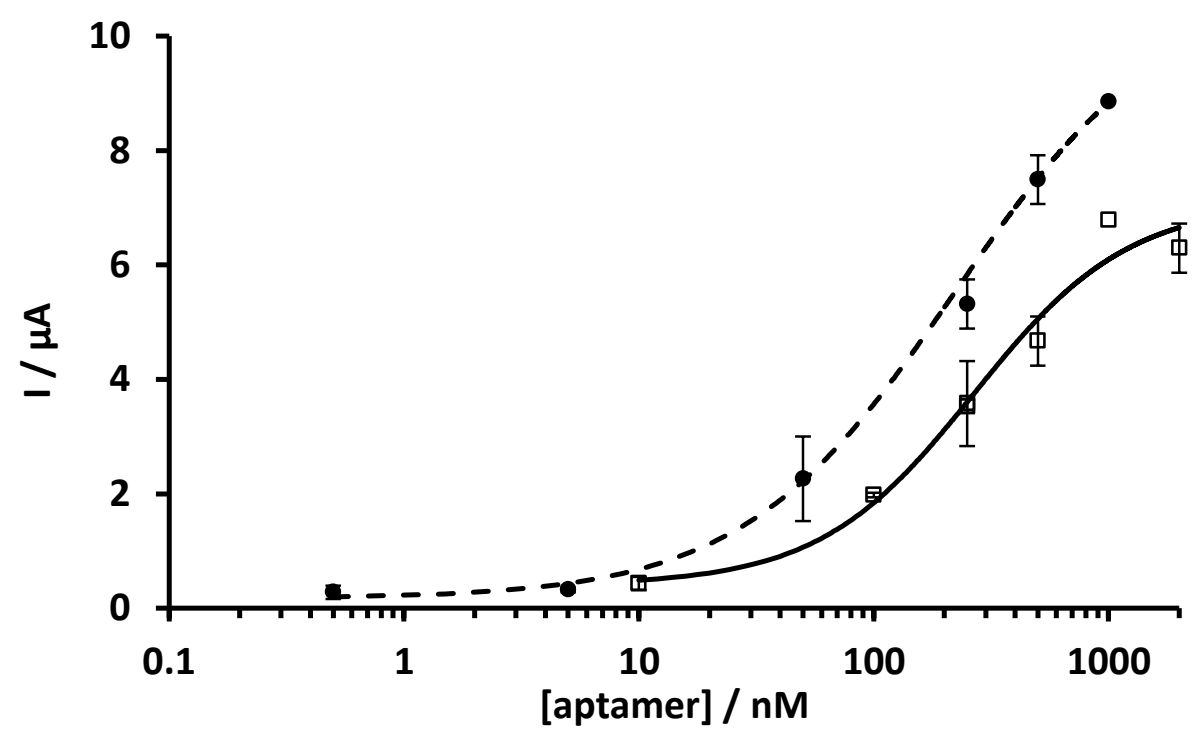


FIGURE 3

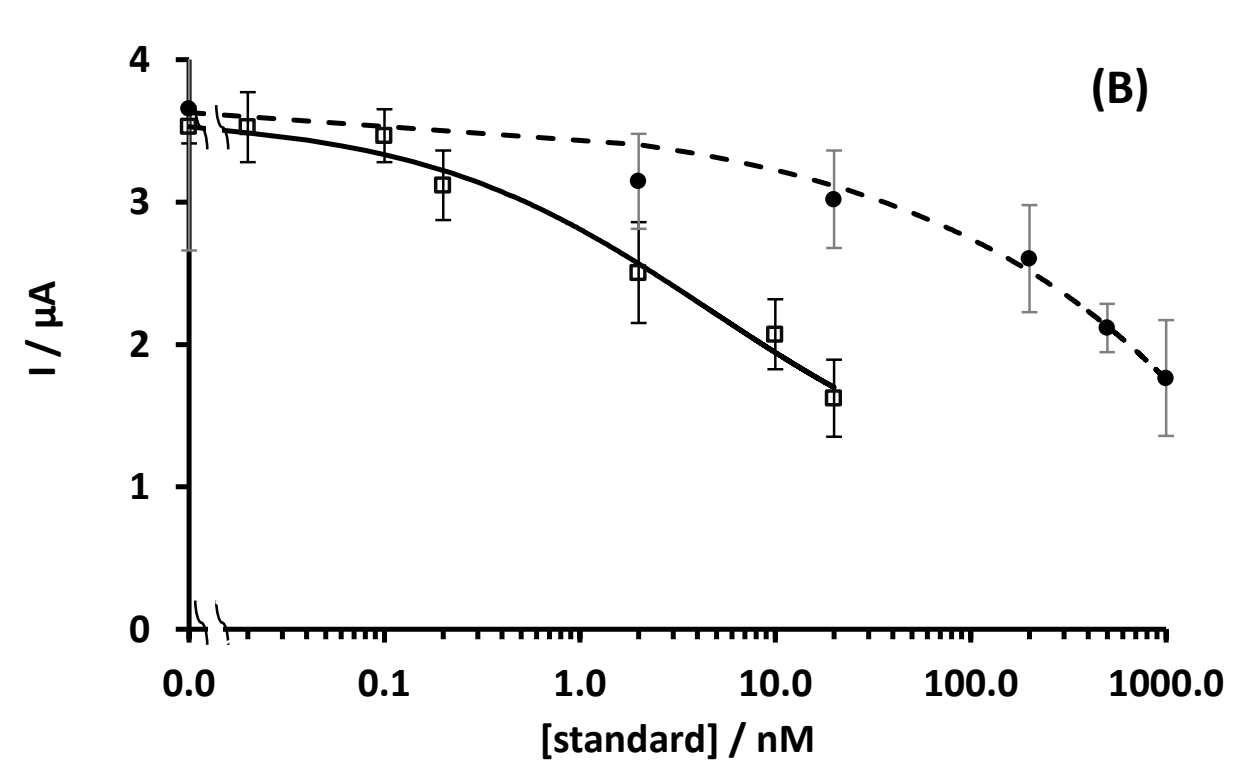

(A)

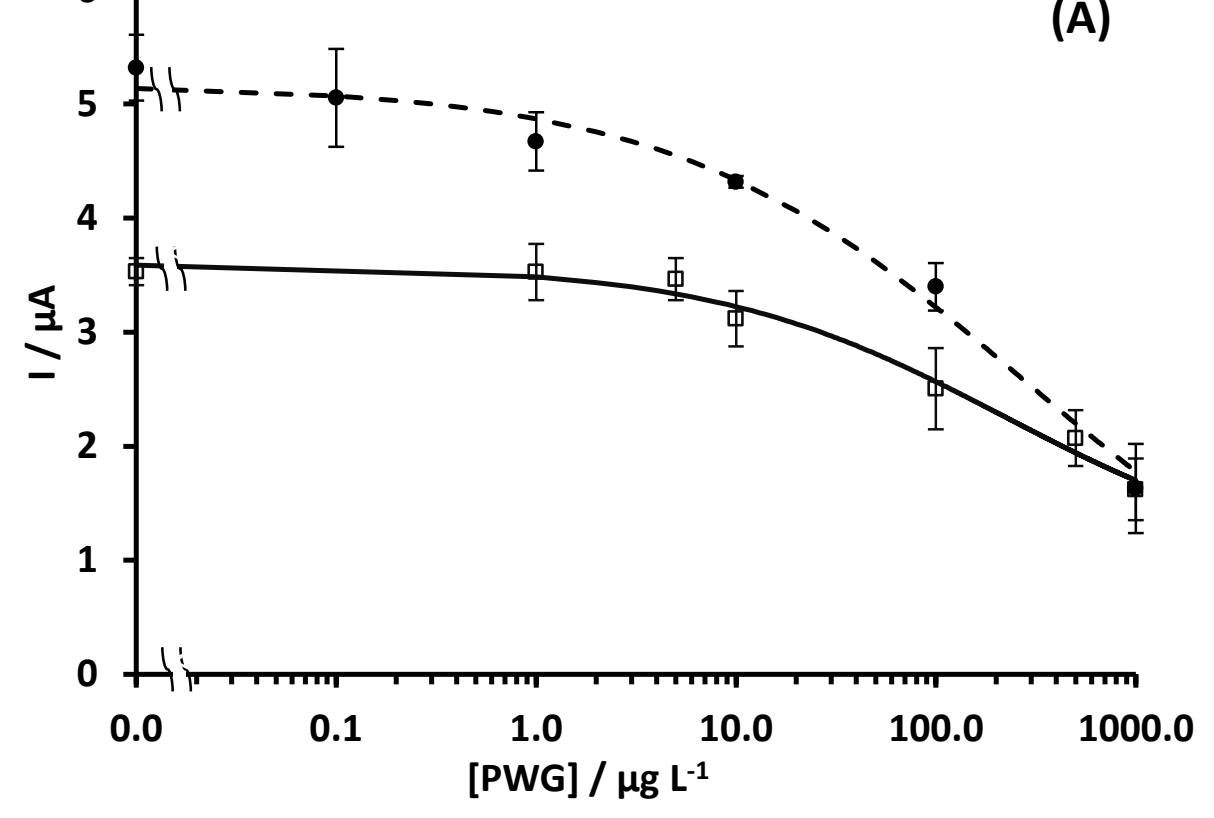


FIGURE 4
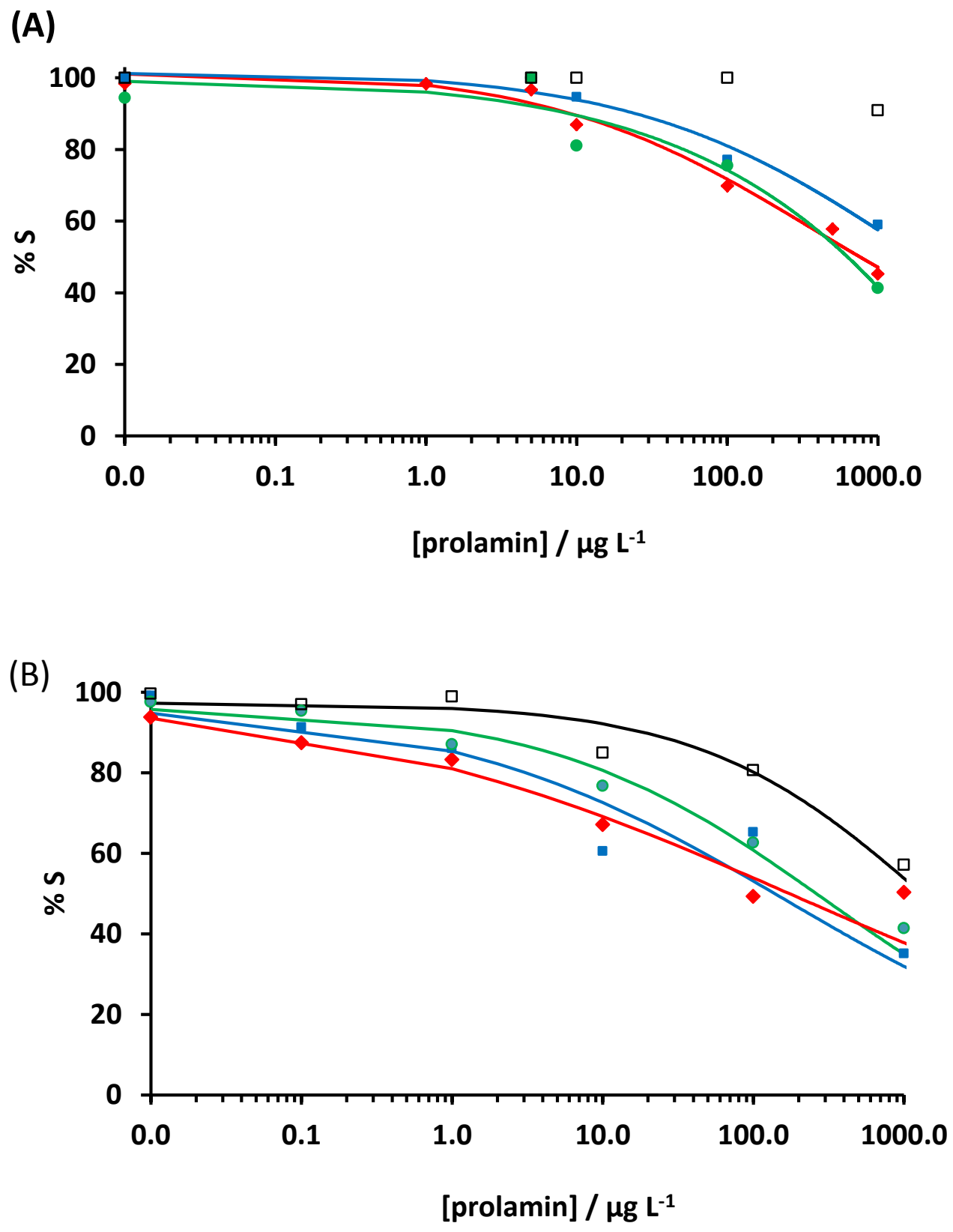